\title{
Oncological Care During First Peruvian National Emergency COVID-19 Pandemic: A Multicentric Descriptive Study
}

\author{
Natalia Valdiviezo', Cindy Alcarraz $\mathbb{D}^{1,2}$, Denisse Castro $\mathbb{D}^{3,4}$, Renzo Salas ${ }^{3}$, Victor Begazo-Mollo ${ }^{5}$, \\ Marco Galvez-Villanueva ${ }^{6}$, Luz Medina Aguirre ${ }^{7}$, Elica Garcia-León (D) ${ }^{8}$, Isela Quispe-Santivañez ${ }^{9}$, \\ Carmen Cornejo-Raymundo $\mathbb{D}^{10}$, Eduardo Paz-Cornejo ${ }^{11}$, Luis Sanchez-Vilela $\mathbb{D}^{12}{ }^{12}$, Vanessa Bermudez- \\ Alfaro ${ }^{13}$, Juan Carlos Vargas-Nina ${ }^{14}$, Carlos Pérez-Ramos ${ }^{15}$, Andrea Meza-Hoces ${ }^{16}$, Paolo R Valdez Barreto ${ }^{17}$, \\ Ruth Huaringa-Leiva ${ }^{18}$, Johanny Muro-Cieza ${ }^{19}$, Valeria Aguilar-Vásquez ${ }^{20}$, Eduardo Yache Cuenca ${ }^{21}$, Silvia Neciosup- \\ Delgado', Nathaly Poma-Nieto ${ }^{22}$, Sheyla Chavez-Gavino ${ }^{23}$, Lenin Fernandez-Rosas ${ }^{24}$, Jhajaira M Araujo $\mathbb{D}^{2}$, \\ Eduardo Payet ${ }^{25}$, Henry L Gomez'
}

\begin{abstract}
'Departamento de Medicina Oncológica, Instituto Nacional de Enfermedades Neoplásicas, Lima, I5038, Peru; ${ }^{2}$ Escuela Profesional de Medicina Humana, Universidad Privada San Juan Bautista, Lima, Perú; ${ }^{3}$ Departamento de Oncología Médica, Hospital Nacional Edgardo Rebagliati Martins, Lima, 15072, Peru; ${ }^{4}$ Centro de Investigación de Medicina de Precisión, Universidad de San Martin de Porres, Lima, I5024, Peru; ${ }^{5}$ Departamento de Medicina Oncológica, Instituto Regional de Enfermedades Neoplásicas Sur, Arequipa, Perú; ${ }^{6}$ Departamento de Medicina Oncológica, Instituto Regional de Enfermedades Neoplásicas Norte, La Libertad, Perú; ${ }^{7}$ Departamento de Medicina Oncológica, Hospital Goyeneche, Arequipa, 04600, Perú; ${ }^{8}$ Departamento de Medicina Oncológica, Hospital Regional de Lambayeque, Lambayeque, I400I, Perú; ' Departamento de Medicina Oncológica, Hospital Santa Rosa, Lima, 15084, Peru; ${ }^{10}$ Departamento de Medicina Oncológica, Hospital Nacional Dos de Mayo, Lima, Peru; ${ }^{~ ' D e p a r t a m e n t o ~ d e ~}$ Medicina Oncológica, Hospital Nacional Alberto Sabogal Sologuren, Lima, Peru; ${ }^{12}$ Departamento de Medicina Oncológica, Hospital de Apoyo II Santa Rosa, Piura, Peru; ${ }^{13}$ Departamento de Medicina Oncológica, Hospital Nacional Guillermo Almenara Irigoyen, Lima, I5033, Peru; ${ }^{14}$ Departamento de Medicina Oncológica, Hospital II EsSalud de Cajamarca, Cajamarca, Peru; ${ }^{15}$ Departamento de Medicina Oncológica, Hospital María Auxiliadora, Lima, Peru; ${ }^{16}$ Departamento de Medicina Oncológica, Hospital II E de Lamas, San Martin, Peru; ${ }^{17}$ Departamento de Medicina Oncológica, Hospital de Alta complejidad Virgen de la Puerta, La Libertad, Peru; ${ }^{18}$ Departamento de Medicina Oncológica, Hospital Militar Central, Lima, Peru; ${ }^{19}$ Departamento de Medicina Oncológica, Hospital Regional Docente de Cajamarca, Cajamarca, Peru; ${ }^{20}$ Departamento de Promoción de la Salud, Prevención y Control del Cáncer, Instituto Regional de Enfermedades Neoplásicas Norte, La Libertad, Perú; ${ }^{21}$ Departamento de Epidemiología, Instituto Regional de Enfermedades Neoplásicas Norte, La Libertad, Perú; ${ }^{22}$ Departamento de Medicina Oncológica, Hospital Nacional Daniel Alcides Carrión, Lima, Perú; ${ }^{23}$ Departamento de Medicina Oncológica, Hospital Regional Eleazar Guzmán Barrón, Ancash, Perú; ${ }^{24}$ Departamento de Cirugía Oncológica, Hospital Regional Eleazar Guzmán Barrón, Ancash, Perú; ${ }^{25}$ Jefatura Institucional, Instituto Nacional de Enfermedades Neoplásicas, Lima, I5038, Peru
\end{abstract}

Correspondence: Natalia Valdiviezo, Departamento de Medicina Oncológica, Instituto Nacional de Enfermedades Neoplásicas, Av. Angamos 2520, Surquillo, Lima, I5038, Peru, Tel +5I 992825055, Email nivaldivieso@gmail.com

Purpose: The aim of this study is to evaluate the oncological care during the first state of national emergency due to the COVID-19 pandemic in several public cancer hospitals in Peru.

Materials and Methods: A multicentric cross-sectional descriptive study was conducted by interviewing adult cancer patients diagnosed and treated between January 2019 and February 2020 from 18 hospitals. This study was carried out in September 2020, the last month of the first state of national emergency. Demographic and clinical characteristics were evaluated, including COVID-19 status and cancer treatment features.

Results: A total of 1472 patients were included; the median age was 55 years (range 19-97). Most patients $(85.8 \%, \mathrm{n}=1263)$ had solid neoplasia, $13.5 \%(\mathrm{n}=198)$ hematologic neoplasia, and $0.7 \%(\mathrm{n}=11)$ others. SARS-CoV-2 infection was confirmed in $8.6 \%(\mathrm{n}=126)$, $1.2 \%(\mathrm{n}=18)$ were probable, $1.6 \%(\mathrm{n}=24)$ suspected, and $88.6 \%(\mathrm{n}=1304)$ negative cases. Overall, $51.6 \%$ of patients $(\mathrm{n}=759)$ had cancer treatment delays, $42.5 \%(\mathrm{n}=626)$ changed treatment delivery (endovenous to oral systemic therapy), and $12.6 \%(\mathrm{n}=185)$ of cases cancer therapy was discontinued. In total, $10.3 \%(\mathrm{n}=117)$ of patients whose disease was controlled or in remission, experienced progression of disease during the state of emergency. A total of $6.7 \%(\mathrm{n}=98)$ of patients died, of whom $73.5 \%(\mathrm{n}=72)$ died from disease progression; $18.4 \%(\mathrm{n}=18)$ from SARS-CoV-2 infection and 8.1\% $(\mathrm{n}=8)$ from undetermined causes. Patients with hematological malignancies [hazard ratio (HR): 5.11 (95\% confidence interval (CI): 1.99-13.07)] and no response to therapy before the onset of the pandemic [5.01 (1.44-17.42)] had an increased risk of death among COVID-19 infected individuals, whereas advanced clinical stage [5.09 (2.37-10.95)] and discontinuation of treatment [3.66 (1.97-6.78)] were risk factors among non-COVID-19 patients. 
Conclusion: Our study suggests that the COVID-19 pandemic has an adverse impact on the outcomes of Peruvian cancer patients. In our cohort, cancer mortality was higher than COVID-19 disease mortality.

Keywords: COVID-19 pandemic, cancer care, Peru

\section{Introduction}

Cancer represents the leading cause of mortality in Peru; ${ }^{1}$ due to this, the number of oncologic centers has increased, favoring the decentralization of cancer care during the past decade. ${ }^{2}$ However, in Peru, since the beginning of the COVID-19 pandemic, restrictive measures have been implemented to prevent its spread. On March 15, 2020, a state of national emergency was declared. These measures included home confinement, national travel ban, and the closure of ambulatory centers and outpatient services closure. During the first few months of the pandemic, Peru reorganized the healthcare services with public hospitals giving priority to patients with COVID-19 infection, redeploying physicians to pandemic tasks, and postponing elective therapies.

In Peru, the first state of national emergency was between March and September 2020; during this time, the care provided to new cancer patients significantly decreased due to measures implemented to avoid the spreading of the virus and the increased risk of mortality for immunocompromised individuals. Early reports showed that cancer patients had higher rates of death from COVID-19 (7.6-36\%) compared to the general population $(1.4-2.3 \%) .^{3-5}$ For this reason, many centers adopted new standards of treatment to reduce patients' exposure to coronavirus but without compromising patients' outcomes. ${ }^{6-8}$

There is a lack of data about cancer care during the COVID-19 pandemic in Peruvian patients. Furthermore, there are not many multicentric studies that evaluate the public health system concerning the effects of the pandemic in cancer patients. On the other hand, focus on COVID-19 management will left behind another non-communicable diseases (NCDs) such as cancer. This increase of NCDs will create a vicious circle between the two pandemics - the NCDs and COVID-19-thus exacerbating health inequities. ${ }^{9}$ Therefore, our aim was to evaluate the oncologic care during the first state of national emergency due to the COVID-19 pandemic in several Peruvian public cancer hospitals as well as to describe the clinical features, outcomes and death of the cancer patients treated during this time.

\section{Materials and Methods}

\section{Study Design}

A multicentric descriptive cross-sectional study.

\section{Setting}

This study was conducted during September 2020, the last month of the first state of national emergency in Peru.

The participating centers belonged to the health network of the Social Security of Health in Peru (EsSalud), the National Ministry of Health (MINSA) and the Peruvian Armed Forces.

\section{Participants}

The inclusion criteria were patients aged 18 years and older with de novo cancer diagnosis and treated between January 2019 and February 2020 in any of the 18 public cancer centers (Supplementary Table 1S), patients able to understand and answer a questionnaire (Supplementary Figure 1S) and patients who accepted and signed informed consent. Patients under palliative care and those who died before March 2020 were excluded. The STROBE (The Strengthening the Reporting of Observational Studies in Epidemiology) guidelines were followed (Supplementary Table 2S).

\section{Variables and Data Sources/Measurement}

COVID-19 status was defined according to the Peruvian Ministry of Health recommendations ${ }^{10}$ and classified into 4 categories: 1) Suspicious case: a) person with an acute respiratory infection, presenting two or more of the following 
symptoms: cough, throat pain, difficulty breathing, nasal congestion, fever, and who has one of the following conditions: any contact with a confirmed case of COVID-19 infection within 14 days before the onset of symptoms; or residence or travel history in a district of Peru with the presence of autochthonous cases of COVID-19 in the 14 days prior to the onset of symptoms; or history of travel or residence 14 days before the onset of symptoms in countries with community transmission; b) person with a serious acute respiratory infection (ARI): fever over $38^{\circ} \mathrm{C}$, cough, respiratory distress, and requiring hospitalization; 2) Probable case: a suspected case with a positive laboratory result for COVID-19 in a nonconfirmatory test or with an indeterminate result; 3) Confirmed case: a person with a confirmatory laboratory test of COVID-19 infection, regardless of clinical signs and symptoms. And 4) No case: patient whose COVID-19 infection has been ruled out due to a laboratory result.

Demographic and clinical characteristics recorded in the medical records were retrieved, these included 1) type of cancer: solid or hematological cancer; 2) clinical staging at diagnosis: early (stage I-II) or advanced (stage III-IV); 3) neoplasia status before the pandemic: controlled disease (cancer activity without increase), disease in progression, or disease in remission (accordingly to cancer type); 4) COVID-19 (see above); 5) changes in cancer treatment administration: delay of cancer treatment (patient does not receive their treatment in the frequency according to plan/scheme), modification of therapy delivery date (change of date to one subsequent to the one initially provided, this last is not necessary according to scheme), change from intravenous to oral chemotherapy, discontinuation of chemotherapy (any medical interruption), missing appointments, and changing to a different healthcare provider (private health center); 6) current cancer status (in accordance to cancer criteria response indicated in patients records), and 7) cause of death (from COVID-19, cancer-related or other).

Additionally, we designed a questionnaire about cancer (diagnosis date, type, treatment) and COVID-19 diagnosis (Supplementary Figure 1S). The questionnaire was validated through expert judgment by all researchers.

The survey was performed by one of every cancer center (18 researchers), previous informed consent, by a telephone call during September 2020. The patients or their families did respond the questions in case of medical limitation or death of the patient. The survey administration time was according to every researcher discretion.

The information from both the informed consent and questionnaires were stored and coded using non-identifiable codes (COVID-0001, COVID-0002, sequentially). An identification record was used to keep track of the patient's name and code. The data recorded in the data collection sheets were entered into a structured database in Microsoft Excel 2010 software. An internal assessment was carried out to verify the consistency of the collected data.

\section{Bias}

Standardized questionnaires and also preexisted records (medical records) for the corroboration of clinical information were used in order to avoid recall bias.

\section{Study Size}

The sample size for an infinite population was 1421 patients with a confidence level of $95 \%$ and a precision of $2.6 \%$ for an expected proportion of 0.5 .

\section{Quantitative Variables}

The age was sized in years considering the birth date of the medical records, in order to associate age with other variables. Researchers chose the cut-off age 60 years, because the cancer clinical guidelines made different recommendations according to these two age groups ( $\geq$ or $<60$ years).

\section{Statistical Methods}

Sex, cancer type, clinical stage at diagnosis, response to treatment, and characteristics related to treatment adherence were reported through frequencies and percentages. Summary measures (median, minimum and maximum) were used to describe age. The Chi-square test was used to test the hypothesis of independence of each of the clinical characteristics and those that refer to adherence to treatment and vital status, applying the Yates correction and Fisher's exact test when 
appropriate. $t$-test was used to compare two groups in quantitative variables in a normal distribution and Mann Whitney Wilcoxon in non-normal distribution.

Logistic regression models were used to analyze the effect of clinical characteristics and adherence to treatment on vital status (alive/deceased), including in the models the characteristics that rejected the independence hypothesis. This effect was calculated through odds ratio (OR) and $95 \%$ confidence intervals, unadjusted and adjusted for confounding characteristics. A p-value $<0.05$ was considered statistically significant. The analysis was done using the statistical program SPSS Statistics version 22.0.

\section{Ethical Aspects}

Informed consent from the patient, the legal guardian, or both was obtained to participate in the study. The data was securely and anonymously stored. The research project was approved by Institutional Review Boards at each participating institution and complied with the Declaration of Helsinki.

\section{Results}

\section{Patients and Clinical Features}

A total of 1828 patients were identified, and 356 patients were excluded (Figure 1). A total of 1472 patients were included for analysis. The majority of patients came from cities located on the coast of Peru (Lima, Arequipa, and La Libertad), and the Instituto Nacional de Enfermedades Neoplasicas (INEN) had the highest number of new patients. The median age at diagnosis was 55 years old (range: 19-97), with 59.8\% $(\mathrm{n}=880)$ under the age of 60 years, and $65.1 \%$ $(\mathrm{n}=959)$ were female (Table 1$)$.

Most patients $(\mathrm{n}=1263,85.8 \%)$ had solid tumors, $13.5 \%(\mathrm{n}=198)$ hematologic malignancies, and $0.7 \%(\mathrm{n}=11)$ other cancer types. Most patients had advanced disease $(n=731,55.4 \%$ versus early stage: $n=589,44.6 \%)$; with staging not reported in 152 patients. Response to therapy was, complete response in 29.6\% ( $\mathrm{n}=423)$, stable/partial response in $49.6 \%(\mathrm{n}=709)$, and progressive disease in $20.8 \%(\mathrm{n}=297)$; data was not available in 43 patients.

Most cases were negative for COVID-19 infection $(88.6 \%, \mathrm{n}=1304)$; while $8.6 \%(\mathrm{n}=126)$ were confirmed; $1.2 \%$ $(\mathrm{n}=18)$, probable; and $1.6 \%(\mathrm{n}=24)$ suspected cases.

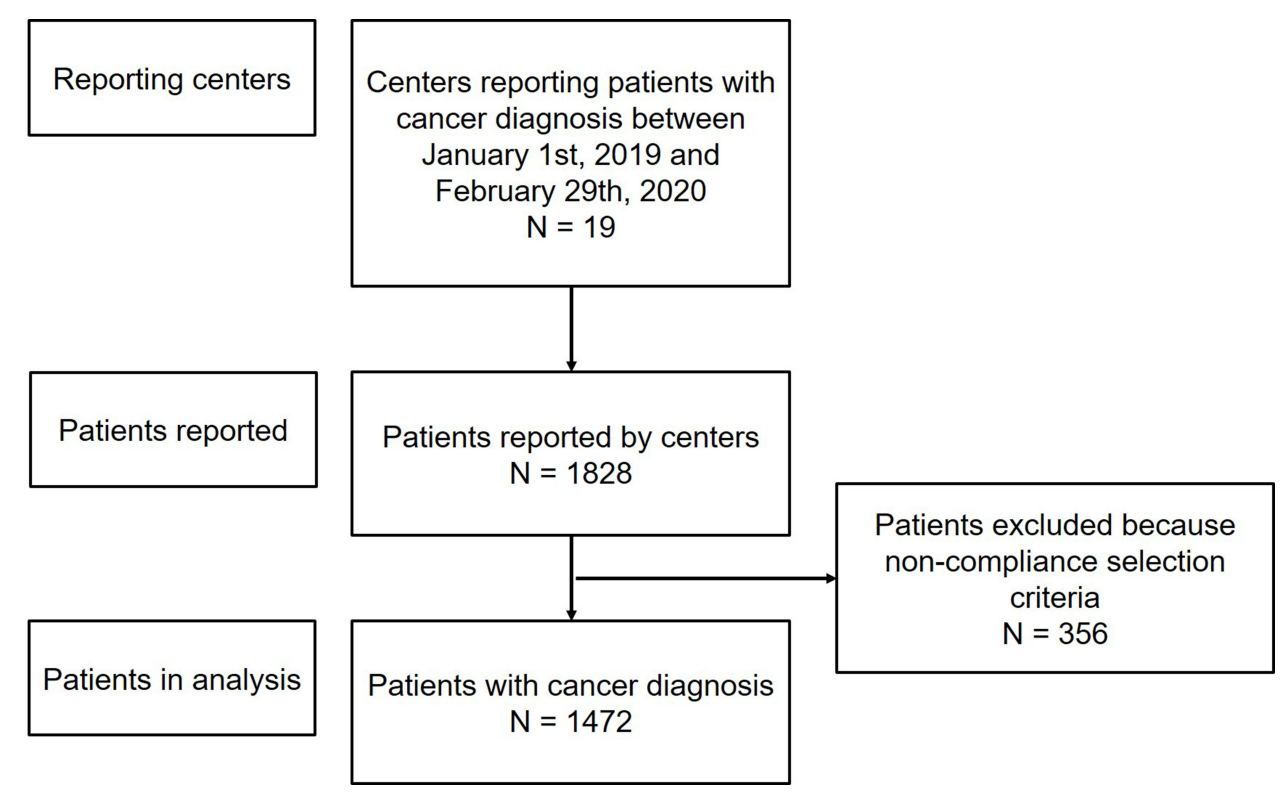

Figure I Participants selection process. 
Table I Clinical Characteristics $(\mathrm{N}=1472)$

\begin{tabular}{|l|c|}
\hline Clinical Features & $\mathbf{N}(\%)$ \\
\hline Age, years & $55[19-97]$ \\
Median [Min-Max] & \\
Age groups & $880(59.8)$ \\
$<60$ years & $592(40.2)$ \\
$\geq 60$ years & \\
Sex & $959(65.1)$ \\
Female & $513(34.9)$ \\
Male & $1263(85.8)$ \\
Cancer types & $198(13.5)$ \\
Solid tumor & $11(0.7)$ \\
Hematologic & \\
Others* & $589(44.6)$ \\
Clinical stage & $731(55.4)$ \\
Early & 152 \\
Advanced & \\
Not reported & \\
Treatment response & \\
before the pandemic & \\
Stable or partial & $709(49.6)$ \\
In remission & $423(29.6)$ \\
Progression & $297(20.8)$ \\
Not reported & 43 \\
\hline
\end{tabular}

Note: *Others: nonmalignant neoplasms.

Abbreviations: Min, minimum; Max, maximum.

\section{Changes in Cancer Treatment Administration}

Cancer-directed therapy was delayed in $51.6 \%(\mathrm{n}=759)$ of patients; the date of treatment delivery was rescheduled in $42.5 \%(\mathrm{n}=626)$, and cancer-directed therapy was discontinued in $12.6 \%(\mathrm{n}=185)$ of the cases. During the study period, $30.6 \%$ of patients $(\mathrm{n}=451)$ were not able to be seen by a cancer specialist after initial diagnosis and referral, and $3.7 \%$ $(\mathrm{n}=54)$ indicated they continued cancer treatment at a private institution (Table 2).

\section{Outcomes and Associated Factors to Death in All Patients}

Of the patients that had response to therapy (ie, complete, partial or stable disease) before the onset of the pandemic, $10.3 \%(\mathrm{n}=117)$ presented disease progression during the COVID-19 pandemic. A total of $6.7 \%(\mathrm{n}=98)$ of patients died, of whom $73.5 \%(\mathrm{n}=72)$ died due to cancer progression; 18.4\% $(\mathrm{n}=18)$ due to COVID-19 infection and 8.1\% $(\mathrm{n}=8)$ due to for a non-specified cause.

In the univariate analysis, age $\geq 60$ years old $(\mathrm{OR}=1.53,95 \% \mathrm{CI}: 1.02-2.31)$; male sex (OR $=1.88,95 \% \mathrm{CI}$ : $1.24-$ 2.83); hematologic malignancy ( $\mathrm{OR}=3.14,95 \% \mathrm{CI}$ : $1.98-4.97)$; advanced clinical stage (OR $=5.17,95 \%$ CI: $2.78-$ 9.63); COVID-19 infection ( $\mathrm{OR}=3.95,95 \% \mathrm{CI}: 2.48-6.29)$; change from intravenous to oral chemotherapy (OR $=2.29$ 95\% CI: $1.26-4.19)$, and cancer therapy discontinuation ( $\mathrm{OR}=4.08,95 \% \mathrm{CI}: 2.59-6.41)$ were risk factors for death. In the multivariate analysis, age, cancer subtype, advanced clinical stage, COVID-19 infection, and cancer therapy discontinuation were independent prognostic factors for death (Table 3).

\section{Outcomes and Associated Factors to Death in COVID-I 9 Patients}

Within the COVID-19 infected individuals $(\mathrm{n}=168), 17.9 \%(\mathrm{n}=30)$ died. In the univariate analysis, age $\geq 60$ years old $(\mathrm{OR}=2.30,95 \% \mathrm{CI}: 1.03-5.13)$; hematologic malignancy $(\mathrm{OR}=3.76,95 \% \mathrm{CI}: 1.61-8.79)$ and progressive disease before the pandemic $(\mathrm{OR}=4.06,95 \% \mathrm{CI}: 1.29-12.77)$ were associated to death. In the multivariate analysis, 


Table 2 Cancer
Administration (N= Treatment
\begin{tabular}{|l|c|}
\hline Variable & N (\%) \\
\hline Treatment delay & \\
Yes & $759(51.6)$ \\
No & $713(48.4)$ \\
Appointment date & \\
change & \\
Yes & $626(42.5)$ \\
No & $846(57.5)$ \\
Intravenous to oral CT & \\
switch & $107(7.3)$ \\
Yes & $1365(92.7)$ \\
No & \\
CT discontinuation & $185(12.6)$ \\
Yes & $1287(87.4)$ \\
No & \\
Hospital absenteeism & \\
Yes & $1021(69.4)$ \\
No & \\
Treatment in private & \\
center & \\
Yes & \\
No & $(30.6)$ \\
\hline
\end{tabular}

Abbreviation: CT, chemotherapy.

treatment response before the pandemic and the hematologic malignancy were independent prognostic risk factors (Table 4).

\section{Outcomes and Associated Factors to Death in Non-COVID-19 Patients}

Within the non-COVID-19 patients $(\mathrm{n}=1304), 68(5.2 \%)$ died. Male sex (OR = 1.89, 95\% CI: 1.16-3.08), hematologic malignancy $(\mathrm{OR}=2.49,95 \% \mathrm{CI}: 1.40-4.42)$, advanced clinical stage ( $\mathrm{OR}=5.86,95 \% \mathrm{CI}: 2.76-12.45)$, therapy delay $(\mathrm{OR}=2.01,95 \% \mathrm{CI}: 1.22-3.29)$, and cancer therapy discontinuation ( $\mathrm{OR}=4.57,95 \% \mathrm{CI}: 2.64-7.93)$, were associated to increased risk of death. In the multivariate analysis, clinical stage and cancer therapy discontinuation were independent prognostic factors (Table 5).

\section{Discussion}

This study is a collaborative effort developed due to the unmet need to generate data regarding cancer patients' outcomes during the COVID-19 pandemic in our country.

In this study, the majority of patients belong to main cancer centers of Peru; and probably because these patients have needed to move to larger cities such as Lima, Arequipa, and La Libertad; due to most specialized cancer centers are located in these cities. ${ }^{11}$ This finding clearly shows the Peruvian healthcare system's inequities. ${ }^{12}$ Likewise, poverty and limited access to communication technology played an important role when telemedicine was proposed as an alternative for patient encounters. The patient population attending public hospitals in Peru is low socioeconomic status. Therefore, a significant number of patients could not be reached and could not complete their scheduled visits. This issue has made cancer care and management very difficult in the majority of the regions of Peru ${ }^{13}$ and has been exacerbated during the pandemic. These factors contributed to the inappropriate and delayed management of cancer patients, already described in initial reports. ${ }^{14}$ 
Table 3 Univariate and Multivariate Analysis to Death in All Patients

\begin{tabular}{|c|c|c|c|c|c|c|}
\hline \multirow{2}{*}{$\begin{array}{l}\text { Analysis Type } \\
\text { Variables }\end{array}$} & \multicolumn{3}{|c|}{ Univariate Analysis } & \multicolumn{3}{|c|}{ Multivariate Analysis } \\
\hline & OR not adjusted & $95 \% \mathrm{Cl}$ & $\mathbf{P}$ & OR adjusted & $95 \% \mathrm{Cl}$ & p-value \\
\hline \multicolumn{7}{|l|}{ Age groups } \\
\hline$<60$ years & Ref & & & Ref. & & \\
\hline$\geq 60$ years & 1.53 & $|.02-2.3|$ & 0.042 & 1.63 & $1.0 \mathrm{I}-2.64$ & 0.045 \\
\hline \multicolumn{7}{|l|}{ Sex } \\
\hline Women & Ref. & & & Ref. & & \\
\hline Men & 1.88 & $1.24-2.83$ & 0.003 & 1.25 & $0.77-2.05$ & 0.368 \\
\hline \multicolumn{7}{|l|}{ Type of cancer } \\
\hline Solid tumor & Ref. & & & Ref. & & \\
\hline Hematological & 3.14 & $1.98-4.97$ & 0.001 & 2.50 & $1.34-4.69$ & 0.004 \\
\hline \multicolumn{7}{|l|}{ Clinical stage } \\
\hline Early & Ref. & & & Ref. & & \\
\hline Advanced & 5.17 & $2.78-9.63$ & 0.001 & 4.53 & $2.38-8.62$ & 0.001 \\
\hline \multicolumn{7}{|l|}{ COVID-19 status } \\
\hline No & Ref. & & & Ref. & & \\
\hline Yes & 3.95 & $2.48-6.29$ & 0.001 & 2.37 & $1.36-4.15$ & 0.002 \\
\hline \multicolumn{7}{|l|}{ Appointment date } \\
\hline \multicolumn{7}{|l|}{ change } \\
\hline No & Ref. & & & Ref. & & \\
\hline Yes & 1.51 & $1.00-2.27$ & 0.05 & 1.08 & $0.66-1.77$ & 0.758 \\
\hline \multicolumn{7}{|l|}{ Intravenous to oral } \\
\hline \multicolumn{7}{|l|}{ CT switch } \\
\hline No & Ref. & & & Ref. & & \\
\hline Yes & 2.29 & $1.26-4.19$ & 0.007 & 1.90 & $0.93-3.88$ & 0.077 \\
\hline \multicolumn{7}{|l|}{ CT discontinuation } \\
\hline No & Ref. & & & Ref. & & \\
\hline Yes & 4.08 & $2.59-6.41$ & 0.001 & 2.97 & $1.74-5.07$ & 0.001 \\
\hline
\end{tabular}

Abbreviation: CT, chemotherapy.

Table 4 Univariate and Multivariate Analysis to Death in COVID-19 Cases

\begin{tabular}{|c|c|c|c|c|c|c|}
\hline \multirow{2}{*}{$\begin{array}{l}\text { Analysis Type } \\
\text { Variables }\end{array}$} & \multicolumn{3}{|c|}{ Univariate Analysis } & \multicolumn{3}{|c|}{ Multivariate Analysis } \\
\hline & OR not adjusted & $95 \% \mathrm{Cl}$ & p-value & OR adjusted & $95 \% \mathrm{Cl}$ & p-value \\
\hline \multicolumn{7}{|l|}{ Age groups } \\
\hline$<60$ years & Ref. & & & Ref. & & \\
\hline$\geq 60$ years & 2.30 & $1.03-5.13$ & $0.04 I$ & 2.31 & $0.97-5.54$ & 0.060 \\
\hline \multicolumn{7}{|l|}{ Cancer type } \\
\hline Solid tumor & Ref. & & & Ref. & & \\
\hline Hematological & 3.76 & $1.61-8.79$ & 0.002 & 5.11 & $1.99-13.07$ & 0.001 \\
\hline \multicolumn{7}{|l|}{ Treatment response } \\
\hline In remission & Ref. & & & Ref. & & \\
\hline Stable & 1.28 & $0.42-3.90$ & 0.662 & 1.18 & $0.36-3.85$ & 0.789 \\
\hline Progression & 4.06 & $1.29-12.77$ & 0.017 & 5.01 & $1.44-17.42$ & 0.011 \\
\hline
\end{tabular}

In Peru, during the first COVID-19 outbreak, the incidence rate of COVID-19 infection was estimated at $2.25 \%{ }^{15}$ However, in our study, the incidence of COVID-19 infection in cancer patients was $11.4 \%$, four times higher when compared to the general population. This is consistent with worldwide reports, ${ }^{16}$ such as an Italian cohort with a rate of $7.8 \%,{ }^{17}$ but a higher incidence than those that reported in Spain and China. ${ }^{16,18}$ 
Table 5 Univariate and Multivariate Analysis to Death in Non-COVID-19 Cases

\begin{tabular}{|c|c|c|c|c|c|c|}
\hline \multirow{2}{*}{$\begin{array}{l}\text { Analysis Type } \\
\text { Variables }\end{array}$} & \multicolumn{3}{|c|}{ Univariate Analysis } & \multicolumn{3}{|c|}{ Multivariate Analysis } \\
\hline & OR not adjusted & $95 \% \mathrm{Cl}$ & $\mathbf{P}$ & OR adjusted & $95 \% \mathrm{Cl}$ & p-value \\
\hline \multicolumn{7}{|l|}{ Gender } \\
\hline Female & Ref. & & & Ref. & & \\
\hline Male & 1.89 & $1.16-3.08$ & 0.011 & 1.34 & $0.77-2.33$ & 0.298 \\
\hline \multicolumn{7}{|l|}{ Cancer type } \\
\hline Solid tumor & Ref. & & & Ref. & & \\
\hline Hematological & 2.49 & $1.40-4.42$ & 0.002 & 2.07 & $0.97-4.43$ & 0.062 \\
\hline \multicolumn{7}{|l|}{ Clinical stage } \\
\hline Early & Ref. & & & Ref. & & \\
\hline Advanced & 5.86 & $2.76-12.45$ & 0.001 & 5.09 & $2.37-10.95$ & 0.001 \\
\hline \multicolumn{7}{|c|}{ Appointment date change } \\
\hline No & Ref. & & & Ref. & & \\
\hline Yes & 2.01 & $1.22-3.29$ & 0.006 & 1.52 & $0.86-2.68$ & 0.153 \\
\hline \multicolumn{7}{|c|}{ Chemotherapy discontinuation } \\
\hline No & Ref. & & & Ref. & & \\
\hline Yes & 4.57 & $2.64-7.93$ & 0.001 & 3.66 & $1.97-6.78$ & 0.001 \\
\hline
\end{tabular}

This study found that $6.7 \%$ of cancer patients died during the COVID-19 pandemic, $18 \%$ of them due to SARS-CoV2 infection. An analysis from the United Kingdom predicted that deaths among patients diagnosed with cancer would increase by $20 \%$ a year after the pandemic. ${ }^{19}$ In our cohort, hematologic malignancies were associated with higher mortality risk, similar to China, France, Italy, and the United States cohorts. ${ }^{17,20-23}$ A possible explanation for the worse survival seen in hematologic patients with COVID-19 infection is a more profound state of immunosuppression in these patients as opposed to other cancer types, ${ }^{21,24}$ particularly the state of lymphopenia and neutropenia inherent in these pathologies, which are associated with higher mortality. ${ }^{23}$

Moreover, we found that cancer patients with COVID-19 infection that had poor response to treatment prior to the pandemic had poor survival. Jee et al reported that patients who achieved a complete response or were in remission before the pandemic showed better survival (HR $0.63,95 \%$ CI, 0.41-0.98) than those with active disease at the time of contracting COVID-19 infection. ${ }^{23}$ Another more extensive study found similar results, where patients with active disease did worse (OR $=5.2,95 \%$ CI: $2.77-9.77)$ than patients in remission. ${ }^{4}$ On the other hand, we did not find clinical staging as a risk factor for survival, which differs from Dai et al, who indicated that COVID-19 patients with advanced disease had unfavorable results (OR: 5.58, 95\% CI 1.71-18.2, $\mathrm{p}=0.01$ ). ${ }^{20}$

Regarding cancer patients without COVID-19 infection, the impact of the pandemic was different from those infected; being the cancer progression, advanced stage and discontinuation of cancer therapy the main factors associated with poor survival.

These results demonstrate that the COVID-19 pandemic has a negative indirect impact on patient outcomes due to cancer-directed therapy delays. A North American study showed that all oncological health services were affected, including screening, surgeries, and oncological medical treatments. ${ }^{25}$ Also, New Zealand and Brazil reported that there was a reduction in medical oncology appointments, number of patients undergoing intravenous systemic treatment, and number of hematopoietic stem cell transplants; however, there was an increase in oral-systemic and radiation therapies. ${ }^{26,27}$ Compared to the previous year, these services decreased significantly from March to July $2020,{ }^{25}$ similar to another Peruvian study by Astigueta et al. ${ }^{14}$ Also, we observed in our cohort that approximately $50 \%$ of patients had some delay in cancer treatment.

Hence, based on our results, the authors recommend that cancer-directed therapy should not be postponed during the pandemic in patients with active disease or advanced stage. Previous studies have found that postponing cancer treatment and changes in the management of patients' disease was the main cause of death. ${ }^{14,22}$ Lin et al reported a delay in cancer 
treatment in $49 \%$ of patients and changes in treatment strategy in $30-40 \%$ of cases. ${ }^{28}$ This study found that treatment discontinuation was higher than other series ${ }^{29}$ but similar to that reported in Brazil, ${ }^{27}$ probably due to the Peruvian healthcare system's deficit compared to those in developed countries.

The COVID-19 pandemic has forced us to develop new models of delivering and prioritizing care to cancer patient, being the Telemedicine that has demonstrated encouraging results in several countries. ${ }^{30,31}$ However, in our country, the poor access to telecommunication services has made it difficult to provide care through this strategy during the first wave, which would probably have avoided the majority of hospital absenteeism and poor patient outcomes. Therefore, one of the future group projects is to perform an observational prospective study that will perform the increasing telehealth implementation during the third wave and patient outcomes, which has already been successfully implemented in the main cities of the country after the first wave.

Since the beginning of the pandemic, several guidelines have been published for the management of cancer patients, prioritizing the continuity of treatments with curative intention through modifications in intensity or frequency. ${ }^{29,32,33}$ Likewise, treatments based on prolonged infusions were adapted to administrations of shorter time or lower dose density. ${ }^{7}$ In patients with palliative care, the intravenous treatment was changed to oral, or the treatment was discontinued..$^{6-8}$ In our study, we found that only $7.5 \%$ of patients changed from intravenous to oral delivery, being much lower than that reported in Brazil, where there was an increase in the use of oral chemotherapy of up to $309 \% .^{27}$

Another finding was the high rate of absenteeism in outpatient clinics of up to $30 \%$, which is lower that reported in a Brazilian center (45\%). ${ }^{27}$ The main reasons were home confinement, lack of transportation from rural to urban areas, prioritization of COVID-19 management over cancer care, suspension of scheduled inpatient cancer services, lack of chemotherapy delivery to cancer centers, and suspension of elective surgical procedures, all coupled to a paucity of healthcare providers who were deployed to cover COVID-19 services. Due to the above, some patients in our cohort opted to be treated at a private institution to maintain their cancer care.

This study has limitations mainly related to the nature of the study design. First, public hospitals are not interconnected; therefore, most data are limited to main cancer hospitals but not those located in rural areas, and this could have created a selection bias since most patients living in urban areas usually demonstrate better adherence to therapy than those living in less developed areas. Second, we did not study the impact on mortality of specific disease subtypes, comorbidities, and cancer therapy approaches. Therefore, we can only conclude based on the type of tumor (ie, liquid versus solid) but cannot measure the effects of other important variables such as the use of specific anticancer agents (eg, anti-C20 directed therapy, high-dose chemotherapy) and comorbidities such as diabetes and hypertension. Nonetheless, our main strength is that this is a large collaborative study that included 18 cancer centers in Peru.

\section{Conclusions}

In conclusion, our study suggests that the COVID-19 pandemic has an adverse impact on the outcomes of Peruvian cancer patients, with more deaths related to cancer progression than COVID-19 infection. The presence of hematologic malignancy and non-response to treatment before the pandemic's onset were important risk factors for mortality in COVID-19 infected patients, while advanced clinical stage and discontinuation of cancer treatment were in non-COVID-19 patients. Management of cancer patients in this pandemic constitutes a challenge, which must be carried out within a multidisciplinary team along with public health policies to avoid the COVID-19 disease spread, meanwhile, considering the risk/benefit of cancer treatment. Hence, regarding these observations, our group is currently designing a prospective observational study focusing on the hematological neoplasm population and the causes of worse clinical outcomes during Covid-19 pandemic. Likewise, a prospective study that will perform the increasing telehealth implementation during the third wave and patient outcomes. 


\section{Acknowledgments}

The authors thank each institution's Department of Medical Oncology and are grateful to the participating cancer patients in this study. We would like to thank all the sites that participated in the effort to form the Peruvian network on COVID19 and Dr Shirley Quintana for her contribution to hematological cancer patients.

\section{Author Contributions}

All authors made a significant contribution to the work reported, whether that is in the conception, study design, execution, acquisition of data, analysis and interpretation, or in all these areas; took part in drafting, revising or critically reviewing the article; gave final approval of the version to be published; have agreed on the journal to which the article has been submitted; and agree to be accountable for all aspects of the work.

\section{Disclosure}

All the authors declare that they do not have any conflicts of interest in this work.

\section{References}

1. Zafra-Tanaka JH, Tenorio-Mucha J, Villarreal-Zegarra D, Carrillo-Larco R, Bernabe-Ortiz A. Cancer-related mortality in Peru: trends from 2003 to 2016. PLoS One. 2020;15(2):e0228867. doi:10.1371/journal.pone.0228867

2. Valencia-Mesías G, Rioja-Viera P, Morante-Cruz Z, Toledo-Morote Y, Neciosup-Delgado S, Gómez-Moreno H. The current situation regarding the availability and accessibility of anticancer drugs for breast cancer in the Peruvian public health systems. Ecancermedicalscience. $2021 ; 15$. doi:10.3332/ECANCER.2021.1224

3. Castañeda CA, Castillo M, Rojas-Vilca JL, Fuentes H, Gómez HL. Covid-19 in cancer patients: a systematic review. Rev Peru Med Exp Salud Publica. 2020;37(4):611-619. doi:10.17843/rpmesp.2020.374.5976

4. Kuderer NM, Choueiri TK, Shah DP, et al. Clinical impact of COVID-19 on patients with cancer (CCC19): a cohort study. Lancet. 2020;395 (10241):1907-1918. doi:10.1016/S0140-6736(20)31187-9

5. Rogiers A, Da Silva IP, Tentori C, et al. Clinical impact of COVID-19 on patients with cancer treated with immune checkpoint inhibition. J Immunother Cancer. 2021;9(1):e001931. doi:10.1136/jitc-2020-001931

6. Jazieh AR, Chan SL, Curigliano G, et al. Delivering cancer care during the COVID-19 pandemic: recommendations and lessons learned from ASCO global webinars. JCO Glob Oncol. 2020;6:1461-1471. doi:10.1200/go.20.00423

7. Waisberg F, Enrico D, Angel M, Chacón M. Cancer treatment adaptations in the COVID-19 era. JCO Oncol Pract. 2020;16(6):305-307. doi:10.1200/OP.20.00218

8. Technical document: Management of cancer patients during the COVID-19 pandemic. :; 2020. Available from: https://www.gob.pe/institucion/ minsa/informes-publicaciones/563587-documento-tecnico-manejo-de-pacientes-oncologicos-en-la-pandemia-por-covid-19. Accessed February 21, 2022.

9. Kluge HHP, Wickramasinghe K, Rippin HL, et al. Prevention and control of non-communicable diseases in the COVID-19 response. Lancet. 2020;395(10238):1678-1680. doi:10.1016/S0140-6736(20)31067-9

10. Ministry of Health, Peru.Ministerial resolution N $972-2020-M I N S A ; 2020$. Available from: https://www.gob.pe/institucion/minsa/normas-legales /1366422-972-2020-minsa. Accessed February 21, 2022.

11. Luna-Abanto J, Payet E. Importance and current status of population-based cacer registries in Peru. Rev Medica Hered. 2019;30(2):131-133. doi:10.20453/rmh.v30i2.3558

12. Pinillos-Ashton L. Cancer in Peru: challenges for the millennium. Acta Médica Peru. 2006;23(2):55.

13. Alamo-Palomino IJ, Matzumura-Kasano JP, Gutiérrez-Crespo HF. Patient complaints in the adult emergency department of a tertiary referral hospital. Rev Fac Med Hum. 2020. doi:10.25176/RFMH.v20i2.2916

14. Astigueta-Pérez J, Abad-Licham M, Chávez-Chirinos C, et al. Cancer disease progression and death during the COVID-19 pandemic: a multidisciplinary analysis for the Peruvian setting. Ecancermedicalscience. 2020;14. doi:10.3332/ECANCER.2020.1098

15. Llerena R, Sánchez C. Emergency, management, vulnerability and responses to the impact of the COVID-19 pandemic in Peru. SciELO. 2020:1-16. Available from: https://preprints.scielo.org/index.php/scielo/preprint/view/94/129.

16. Zhang L, Zhu F, Xie L, et al. Clinical characteristics of COVID-19-infected cancer patients: a retrospective case study in three hospitals within Wuhan, China. Ann Oncol. 2020;31(7):894-901. doi:10.1016/j.annonc.2020.03.296

17. Rugge M, Zorzi M, Guzzinati S. SARS-CoV-2 infection in the Italian Veneto region: adverse outcomes in patients with cancer. Nat Cancer. 2020;1 (8):784-788. doi:10.1038/s43018-020-0104-9

18. Sanchez-Pina JM, Rodríguez Rodriguez M, Castro Quismondo N, et al. Clinical characteristics of COVID-19-infected cancer patients: a retrospective case study in three hospitals within Wuhan, China. Eur J Haematol. 2020;105(5):894-901. doi:10.1111/ejh.13493

19. Lai A, Pasea L, Banerjee A, et al. Estimating excess mortality in people with cancer and multimorbidity in the COVID-19 emergency. BMJ Open. 2020. doi:10.1101/2020.05.27.20083287

20. Dai M, Liu D, Liu M, et al. Patients with cancer appear more vulnerable to SARS-CoV-2: a multicenter study during the COVID-19 outbreak. Cancer Discov. 2020;10(6):783. doi:10.1158/2159-8290.CD-20-0422

21. Malard F, Genthon A, Brissot E, et al. COVID-19 outcomes in patients with hematologic disease. Bone Marrow Transplant. 2020;55 (11):2180-2184. doi:10.1038/s41409-020-0931-4

22. Albiges L, Foulon S, Bayle A, et al. Determinants of the outcomes of patients with cancer infected with SARS-CoV-2: results from the Gustave Roussy cohort. Nat Cancer. 2020;1(10):965-975. doi:10.1038/s43018-020-00120-5 
23. Jee J, Foote MB, Lumish M, et al. Chemotherapy and COVID-19 outcomes in patients with cancer. J Clin Oncol. 2020;38(30):3538-3546. doi:10.1200/JCO.20.01307

24. Kim JS, Lee KH, Kim GE, et al. Clinical characteristics and mortality of patients with hematologic malignancies and COVID-19: a systematic review. Eur Rev Med Pharmacol Sci. 2020;24(22):11926-11933. doi:10.26355/eurrev_202011_23852

25. Patt D, Gordan L, Diaz M, et al. Impact of COVID-19 on cancer care: how the pandemic is delaying cancer diagnosis and treatment for American seniors. JCO Clin Cancer Informatics. 2020;(4):1059-1071. doi:10.1200/cci.20.00134

26. Gurney JK, Millar E, Dunn A, et al. The impact of the COVID-19 pandemic on cancer diagnosis and service access in New Zealand-a country pursuing COVID-19 elimination. Lancet Reg Heal - West Pacific. 2021;10. doi:10.1016/j.lanwpc.2021.100127

27. Araujo SEA, Leal A, Centrone AFY, et al. Impact of COVID-19 pandemic on care of oncological patients: experience of a cancer center in a Latin American pandemic epicenter. Einstein. 2020;19:eAO6282. doi:10.31744/einstein_journal/2021AO6282

28. Lin DD, Meghal T, Murthy P, et al. Chemotherapy treatment modifications during the COVID-19 outbreak at a community cancer center in New York City. JCO Glob Oncol. 2020;6:1298-1305. doi:10.1200/go.20.00309

29. Li YH, Shen L, Li J. Chemotherapy strategy for colorectal cancer under the outbreak of Corona virus disease 2019. Zhonghua Wei Chang Wai Ke Za Zhi. 2020;23(3):217-219. doi:10.3760/cma.j.cn.441530-20200225-00089

30. Liu R, Sundaresan T, Reed ME, Trosman JR, Weldon CB, Kolevska T. Telehealth in oncology during the COVID-19 outbreak: bringing the house call back virtually. JCO Oncol Pract. 2020;16(6):289-293. doi:10.1200/OP.20.00199

31. Cinar P, Cox J, Kamal A, et al. Oncology care delivery in the COVID-19 pandemic: an opportunity to study innovations and outcomes. JCO Oncol Pract. 2020;16(8):431-434. doi:10.1200/OP.20.00326

32. Ospina Idárraga JA, Martinez-Cordero H, Idrobo Quintero H, et al. Consenso del Grupo de Estudio Latinoamericano de Linfoproliferativos (GELL) para el manejo del Linfoma en estado de Pandemia SARS CoV-2/COVID 19. Rev Colomb Cancerol. 2020;24. doi:10.35509/01239015.690

33. Moujaess E, Kourie HR, Ghosn M. Cancer patients and research during COVID-19 pandemic: a systematic review of current evidence. Crit Rev Oncol Hematol. 2020;150:102972. doi:10.1016/j.critrevonc.2020.102972

\section{Publish your work in this journal}

Cancer Management and Research is an international, peer-reviewed open access journal focusing on cancer research and the optimal use of preventative and integrated treatment interventions to achieve improved outcomes, enhanced survival and quality of life for the cancer patient. The manuscript management system is completely online and includes a very quick and fair peer-review system, which is all easy to use. Visit http://www.dovepress.com/testimonials.php to read real quotes from published authors. 